East African Medical Journal Vol. 81 No 1 January 2004

NEONATAL GASTRIC PERFORATION

R. T.. Kuremu, MBChB, MMed Surg, (Nbi), MMSc (Natal) Lecturer, Department of Surgery, Moi University, G.P. Hadley FRCS (Edinburgh), R. Wiersma, FRCS (Glasgow), MMed Sci. (Natal), Department of Paediatric Surgery, University of Natal, Durban, South Africa

Request for reprints to: Mr. R.T. Kuremu, Department of Surgery, Faculty of Health Sciences, Moi University, P.O. Box 4606, Eldoret, Kenya

\title{
NEONATAL GASTRIC PERFORATION
}

\author{
R.T. KUREMU, G.P. HADLEY and R. WIERSMA
}

\begin{abstract}
Background: Gastric perforation in neonates is a catastrophe associated with high morbidity. Most are due to underlying primary pathology.

Objectives: To review the management of gastric perforation in neonates in Kwa Zulu -Natal, South Africa.

Design: Retrospective study of consecutive complete data sets of neonates presenting with gastric perforation.

Setting: Department of Paediatric Surgery, Nelson R. Mandela School of Medicine, University of Natal, Durban, South Africa.

Subjects: Eight neonates treated for gastric perforation between January 1998 and April 2003.

Main outcome measures: Morbidity and mortality.

Results: There was an equal number of males and females. Median birth weight was $2.0 \mathrm{~kg}$ with a range of 1.4 to $3.2 \mathrm{~kg}$. Five of the eight neonates were premature. Primary pathologies were associated with perforation in seven of the eight neonates. Prematurity, low birth weight and pneumonia were contributing factors to the poor outcome. Sepsis was a complication in seven of the eight neonates leading to their death (88\% mortality). Conclusion: Active perinatal management, early treatment of primary pathologies, and protection of the stomach against distension in neonates at risk are essential in the management of neonatal gastric perforation.
\end{abstract}

\section{INTRODUCTION}

Neonatal gastric perforation is a surgical emergency associated with high mortality(1) accounting for 10$16 \%$ of all neonatal gastro-intestinal tract (GIT) perforations(2). The incidence is higher in males and predominantly affects premature infants(1-5) and usually presents within the first seven days(2). S u r g i c a 1 repair of gastric perforation may be challenging as the whole, or large areas, of the stomach are usually involved by the pathology responsible for the perforation necessitating total, subtotal or segmental gastrectomy (2).

This report reviews eight neonates, part of a larger series of neonatal GIT perforations, managed by the Paediatric Surgical Service of the University of Natal between January 1998 and April 2003.

\section{MATERIALS AND METHODS}

Computer files of neonates admitted with gastric perforation and managed by the Paediatric Surgical Service, University of Natal in Kwa Zulu-Natal were retrieved and analysed.
The data analysed included; patient profile, mode of delivery, presenting features, diagnostic investigations, co-morbid factors, operative details, postoperative complications and outcome.

\section{RESULTS}

Of the eight neonates, four were male and four female. The median birth weight was $2.0 \mathrm{~kg}$ with a range of 1.4 to $3.2 \mathrm{~kg}$. Three neonates were term (38 weeks and over) and five were preterm (under 38 weeks gestation). Seven were delivered per vaginam and one by Caesarean section for foetal distress.

Perinatal conditions identified included polyhydramnios in two mothers (whose babies had oesophageal atresia with tracheo-oesophageal fistula), and one mother who was antibody positive for human immune deficiency virus (HIV). Co-morbid factors are shown in Table 1. Presenting features are shown in Table 2.

Abdominal x-ray in seven neonates, excluding one with gastroschisis, showed free intra-peritoneal air. In one the air had tracked down into the scrotum presenting as bilateral inguinal hernias. 
Table 1

Co-morbid factors

\begin{tabular}{lc}
\hline Co-morbid factor & No. of neonates \\
\hline Prematurity & 5 \\
Small for gestational age & 2 \\
Bronchopneumonia & 2 \\
Hyaline membrane disease (HMD) & 1 \\
Oesophageal atresia & \\
with tracheo-oesophageal fistula & 2 \\
Duodenal atresia & 1 \\
Downs Syndrome & 1 \\
Gastroschisis & 1 \\
\hline
\end{tabular}

Table 2

Presenting features

\begin{tabular}{lc}
\hline Presenting feature & No. of neonates \\
\hline Abdominal distension & 7 \\
Anterior abdominal wall defect & 1 \\
Haematemesis and shock & 1 \\
Respiratory distress & 2 \\
Features of sepsis & 4 \\
Bilious vomiting & 1 \\
Bilateral inguinal hernias & 1 \\
\hline
\end{tabular}

All eight neonates were operated on after stabilisation. In six of the eight, the perforation was on the greater curvature and in two on the anterior wall. Repair was achieved in all, with a gastrostomy added in one who had oesophageal atresia with tracheooesophageal fistula. The atresia was not repaired but fistula was ligated. The decision not to repair the atresia was taken due to poor condition of the neonate. In others the primary pathologies were definitively treated at the same time.

Histology of debrided tissues showed features consistent with necrotising enterocolitis (NEC) in three, one of whom was HIV exposed and had fungal elements (candida and pseudohyphae) within necrotic tissue but not in vascular system. In one neonate no underlying pathology could be determined. This was a term baby but small for gestational age (weight 2.0 $\mathrm{kg}$ ). Perforation was determined as idiopathic. In the remaining four there was a primary pathology responsible for perforation in each - gastroschisis with obstructive compression of herniated bowel, duodenal atresia, and oesophageal atresia with tracheooesophageal fistula $(\mathrm{n}=2)$.

Post-operative complications were sepsis in seven, renal failure in one and respiratory failure in one. Acinetobacter, Pseudomonas, Staphylococcus and Klebsiella were cultured from peritoneal fluid. Seven patients died. The single survivor was one of three with NEC.

\section{DISCUSSION}

Although the numbers are small, the most striking finding of this study is the high mortality. Other studies have reported varied mortality rates ranging from zero $(6,7)$ to $100 \%$ mortality(8). Reports on idiopathic perforations have shown mortality rates at the lower end of the spectrum $(1,7)$.

As reported by other studies(9), gastric perforation is associated with a primary pathology in the majority of neonates. In our experience NEC, duodenal atresia, oesophageal atresia with tracheo-oesophageal fistula, gastroschisis were causal in seven of our patients. Prematurity, low birth weight and respiratory problems (bronchopneumonia and hyaline membrane disease) were significant contributing factors to the poor outcome(10). Bronchopneumonia was already established in the two neonates with oesophageal atresia with tracheooesophageal fistula, an indication of the failure in the pre-operative management of this malformation.

Histology of debrided tissue in one neonate showed abundant yeast forms (candida) and pseudohyphae, and mixed cell infiltrate. The neonate, who was on formula feed because the mother was HIV antibody positive, presented on day four with typical radiological features of NEC with a perforation. Symptoms of poor feeding had started on day two. The challenges posed by HIV in the incidence and management of perforations is likely to be compounded by the introduction and substitution of breast milk by formula feeds, a known risk factor for NEC in its own right(10).

Care directed at reduction of perinatal asphyxia, shock and stress is essential in the prevention of gastric ischaemia and NEC related perforation. The need for advanced life support for infants in the delivery rooms increases with low birth weight(12). The support includes positive pressure ventilation (PPV) which is commonly done by bag and mask, in which gastric ventilation and subsequent distension is one of the inherent problems.

Protection of the stomach against over-distension is necessary in neonates at risk and those requiring ventilation. Passing a nasogastric tube and ensuring free drainage of gastric air and fluid should form part of any resuscitation effort. This allows insufflated air drain thereby decompressing the stomach, improving intramural blood supply, reducing the risk of long ischaemic perforation and allowing fluid resuscitation to restore normal circulation. Successful treatment of a neonate with the added co-morbidity of oesophageal atresia requires continuous active suction of the upper pouch preventing the lethal complication of aspiration pneumonia.

Ventilation of a neonate with respiratory distress syndrome and oesophageal atresia may require manoeuvres to occlude the fistula. Gastric decompression without fistula occlusion will make ventilation impossible by creating a low pressure run-off. 


\section{ACKNOWLEDGEMENTS}

To the Head of Department of Paediatric Surgery for permission to publish this article and Miss Eleanor Conner who provided the secretarial services.

\section{REFERENCES}

1. Chung, M.T., Kuo, C.Y., Wang, J.W., et al. Gastric perforation in the neonate: clinical analysis of 12 cases. Acta. Paediatr. Sin. 1994; 35:565.

2. Pelizzo, G., Dubois, R., Lapillonne, A., et al. Gastric necrosis in newborns: a report of 11 cases. Pediatr. Surg. Int. 1998: 13:346-349

3. Sobel, D.B. Neonatal gastric perforation. Arch. Pediatr. and Adolesc. Med. 1998; 152:599-600

4. Shashikumar, V.L., Bassuk, A., Pilling, G.P. IV and Cresson, S.L. Spontaneous gastric rupture in the newborn: a clinical review of nineteen cases. Ann. Surg. 1975; 82: 22-25

5. Resch, B., Mayr, J., Kuttnig-Haim, M., Reiterer, F., Ritschl, E. and Muller, W. Spontaneous gastrointestinal perforation in very-low-birth-weight infants - a rare complication in a neonatal intensive care unit. Pediatr. Surg. Int. 1998; 13:165-167

6. St-Vil, D., LeBouthillier, G., Luks, F.1., Bensoussan, A.L., Blanchard, H. and Youssef, S. Neonatal gastrointestinal perforations. J. Pediatr. Surg. 1992; 27:1340-1342

7. Jawad, A.J., Al-Rabie, A., Hadi, A., et al. Spontaneous neonatal gastric perforation. Pediatr. Surg. Int. 2002; 18:396-399

8. Wang, Y.J., Shian, W.J., Chang, W.T., Chen, H.C. and Chi, C.S. Clinical observation of neonatal gastrointestinal perforation. Zhonghua Yi Xue Za Zhi. (Taipei). 1994; 53:215-219.

9. Leone R.J. Jr. and Krasna, I.H. 'Spontaneous' neonatal gastric perforation: is it really spontaneous?

10. Grosfeld, J.L., Molinari, F., Chaet, M., et al. Gastrointestinal perforation and peritonitis in infants and children: experience with 179 cases over ten years. Surgery. 1996; 120:650-656.

11. Ricketts, R. Necrotizing enterocolitis. Raffensperger, J.G. (Ed). Swenson's. Paediatric Surgery 5th Edition. Appleton and Lange Publications, Connecticut. 1990. pp625-636.

12. Vadhera, R.B. The use of LMA in newborn resuscitation. Internet J. Anaesth. 1997; 1.(4). 